stomatologie 2013 [Suppl 1] $\cdot 110: 8-8$ DOI 10.1007/s00715-013-0258-5

(C) Springer-Verlag Wien 2013

\title{
Grußworte
}

\section{des Bundespräsidenten}

Ich gratuliere zur vorliegenden Festschrift anlässlich des 150-jährigen Bestehens der Österreichischen Gesellschaft für Zahn-, Mund- und Kieferheilkunde (ÖGZMK), die ich mit Dank und Anerkennung für das langjährige Engagement im Dienste der Gesundheit der Österreicherinnen und Österreicher verbinden möchte.

Die Ärztinnen und Ärzte haben viel geleistet in diesen 150 Jahren und ich finde es sehr berechtigt, dass dieses bemerkenswerte Jubiläum mit einer eindrucksvollen Rückschau gefeiert wird. So erhalten die interessierten Leserinnen und Leser nicht nur einen Einblick in die wechselvolle Geschichte der Zahn-, Mund- und Kieferheilkunde, sondern auch in interessante Ergebnisse praxisrelevanten Wissens.

Ich nütze die Gelegenheit, den Zahnärztinnen und Zahnärzten meinen Dank und meine Anerkennung auszusprechen. Die Gesundheit zu erhalten, wird angesichts der hohen Lebenserwartung ein immer wichtigeres Thema.
Als Ärztinnen und Ärzte nehmen Sie in besonderer Weise Ihre Verantwortung wahr - so wie auch die Politik das wachsende Interesse und das Gesundheitsbewusstsein in der Gesellschaft zu fördern verpflichtet ist.

Ich gratuliere nochmals herzlich zur schönen Jubiläumsschrift und wünsche der ÖGZMK alles Gute für die Zukunft!

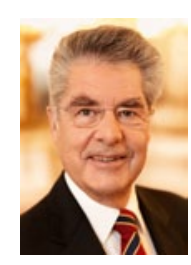

Dr. Heinz Fischer Bundespräsident 